\title{
Quality assessment of clinical education services in teaching hospitals located in Kerman, Iran
}

\author{
Vahid Yazdi-Feyzabadi1 ${ }^{1,2}$, Mohammad Hossein Gozashti ${ }^{3}$, Samane Komsari ${ }^{4}$, Sedigheh Mohammadtaghizadeh ${ }^{4}$, \\ Mohammadreza Amiresmaili ${ }^{5}$
}

\footnotetext{
${ }^{1}$ Department of Health Management and Economics, School of Public Health, Tehran University of Medical Sciences, Tehran, Iran

${ }^{2}$ Health Services Management Research Center, Institute for Futures Studies in Health, Kerman University of Medical Sciences, Kerman, Iran

${ }^{3}$ Department of Endocrinology, Physiology Research Center; Kerman University of Medical Sciences, Kerman, Iran

${ }^{4}$ Research Center for Modeling in Health, Institute for Futures Studies in Health, Kerman University of Medical Sciences, Kerman, Iran

${ }^{5}$ Medical Informatics Research Center, Institute for Futures Studies in Health, Kerman University of Medical Sciences, Kerman, Iran
}

\section{Type of article: Original}

\begin{abstract}
Introduction: Clinical education is one of the most important components of the resource generation function of health systems, and it has a very important role in graduates' competency with respect to effective, practical education. This study aimed to assess the quality of clinical services in Kerman's teaching hospitals located in southeastern Iran.

Methods: This cross-sectional study was conducted in 2011 on 303 medical students at different levels of medical education at Kerman's teaching hospitals. A modified SERVQUAL instrument was used to collect the data after its validity and reliability were checked. The data were analyzed by SPSS 18.0 using the paired t-test, Kruskal-Wallis, and post hoc tests, when appropriate.

Results: In all five dimensions of quality, gaps were observed between students' perceptions and expectations as follows: Assurance (mean = -1.18), Responsiveness (-1.56), Empathy (-1.4), Reliability (-1.27), and Tangibles (1.21). There was a significant difference between the quality perceptions and expectations of the medical students $(\mathrm{p}<0.001)$. A significant difference was observed between three educational levels, including externships, internships, and assistantships regarding the dimensions of the quality gaps $(\mathrm{p}<0.001)$.

Conclusion: The clinical services provided by teaching hospitals in the study did not meet the students' expectations at any of the three educational levels. As we precisely assessed the dimensions and items that had the higher quality gaps, it was apparent that, for most part, clinical education officials could improve the quality by designing interventions, which would not be very difficult to do.

Keywords: SERVQUAL, clinical education, quality assessment, teaching hospital, Iran
\end{abstract}

\section{Introduction}

Clinical education involves a variety of learning fields related to the issues of community health and illness. Since performance leadership in the healthcare system depends on the knowledge, skills, and abilities of the graduates, education is regarded as the cornerstone of healthcare reform to meet the actual needs of the community $(1,2)$. It is believed that quality is a relative and challenging concept (3) without a common definition that can be applied in all fields. It is a highly-debated concept with multiple meanings to different people who deal with higher education (4).

\section{Corresponding author:}

Associate Professor Dr. Mohammadreza Amiresmaili, Department of Health Management and Economics, School of Health management and medical informatics, Kerman University of Medical Sciences, Kerman, Iran,

Tel: +98.9126936504, E-mail: mohammadreza.amiresmaili@gmail.com

Received: June 05, 2015, Accepted: August 17, 2015, Published: November 2015

iThenticate screening: August 17, 2015, English editing: September 25, 2015, Quality control: October 05, 2015

(C) 2015 The Authors. This is an open access article under the terms of the Creative Commons Attribution-NonCommercialNoDerivs License, which permits use and distribution in any medium, provided the original work is properly cited, the use is non-commercial and no modifications or adaptations are made. 
As higher education organizations struggle for competitive advantage and high-quality services, evaluating the quality of educational services is an important motivation because it allows the provision of feedback on the effectiveness of educational plans and their implementation (5). At the beginning of the twenty-first century, medical schools assumed that it would be adequate to teach the basic and clinical sciences and the required technical skills to medical students. Thus, hospitals affiliated with medical schools emerged as the field for teaching clinical skills (6). In 1985, in an effort to improve medical education and health research and to generate the human resources required to meet the health needs of the country, the Islamic Parliament of Iran (Majlis) passed a law establishing the Ministry of Health and Medical Education. As a result, medical education was merged with the provision of healthcare services. At the provincial level, entities called medical universities were established, and they were in charge of providing healthcare services, medical education, and research in their defined territories (7). Universities generally emphasize responding to students' expectations and demands, and this makes them more student-oriented than service-oriented, resulting in the students' perceptions of higher education services being given more importance than the actual provision of healthcare services (8). Among different methods used to measure quality (9), currently, throughout the world, students' perspectives are studied concerning all of the dimensions of a medical education $(10,11)$. Providing high quality healthcare depends significantly on providing high-quality medical education $(12,13)$. Providing systematic services when encountering new clinical situations necessitates receiving feedback from medical students to ensure high-quality services (14). De Oliviera \& Ferreira, in a study conducted in 2009 in Brazil, suggested that the quality-related problems of higher education in developing countries are serious. To change this scenario, an investment in high-quality systems is necessary. One option is SERVQUAL, which is used to measure the gap between the expectations and perceptions of service quality, as well as planning for improvement (15). SERVQUAL is a popular instrument that was proposed by Parasuraman for measuring the quality of service (16), and it has been tested and used to measure educational service quality (17-19). In the SERVQUAL approach, the customer evaluates the quality of services using five criteria, which are tangibles, assurance, responsiveness, empathy, and reliability. This approach consists of the concepts of perceptions and expectations, with perceptions dealing with the status quo of educational services and expectations dealing with the ideal status of educational services. Service gaps result from the differences between expectations and perceptions (20). The first step in decreasing the probable gap is to identify students' perceptions and expectations regarding educational services. This information can be used to facilitate informed prioritization and allocation of strategic resources and to provide a basis for improving the services that are provided, by increasing their effectiveness and ensuring the satisfaction of the recipients of the services (21). As the Iranian strategy concerning the development of universities has shifted from quantitative to qualitative aspects, the necessity of performing such studies is more obvious. In addition, Iranian studies on this topic are rare, and no study has been done in the teaching hospitals. Thus, this study was conducted to determine the quality of the educational services in the teaching hospitals of a medical university in southeastern Iran.

\section{Material and methods}

This cross-sectional study was performed in 2011 with 303 medical students at teaching hospitals affiliated with the Kerman University of Medical Sciences (KUMS) in southeastern Iran. This study was based on a census of all medical students who were studying in academic year 2011-2012 at each of the three levels of medical education, i.e., externship (third to fifth year of general practice education), internship (sixth and seventh year of general practice education), and assistance (specialty medical education). SERVQUAL is an instrument that can identify the quality gap between the expectations and perceptions of service received, and it was used to collect the data in this study. An original questionnaire based on Aghamolaei \& Zare (22) in an educational environment was a a very important component of our study. However, to be more suitable for clinical environments, some modifications were made in the original instrument. The validity of the modified instrument was verified through a two-stage face validity method in which the original questionnaire with 22 items was distributed among 10 experts in the clinical education field. In the first stage, compatibility, relevant questions, and the main ideas were incorporated in the questionnaire. In the second stage, the modified questionnaire was distributed among the mentioned group of experts again, and, then, the final instrument was verified. We also tested the reliability of the instrument, which was confirmed by Cronbach's alpha in a pilot study with 30 members of the study's population. The coefficients of Cronbach's alpha were estimated to be $0.79,0.91,0.89,0.91$, and 0.80 for assurance, responsiveness, empathy, reliability, and tangibles dimensions, respectively. The overall coefficient for the SERVQUAL measure was estimated to be 0.96 . The modified SERVQUAL instrument was made up of 26 parallel items that were rated using a 7-point Likert scale. The instrument was used tio measure five postulated dimensions of service quality, which consisted of tangibles (4 items), reliability (6 items), responsiveness (5 items), assurance (5 items), and empathy (6 
items). The distribution of the questionnaires was coordinated with the education officer of every teaching hospital involved in the study. The participants were assured that the information provided would be kept confidential. Then, we explained the aims of the research to them and acquired their verbal consent to participate before proceeding with the questionnaire. This study was approved by the Ethics Committee of KUMS. Data analyses were performed using descriptive statistics (mean, standard deviation, and frequency) and analytical statistics (paired-samples t-test, Kruskal-Wallis test, and post hoc tests) when appropriate using SPSS version 18 (SPSS, Inc., Chicago, Illinois, USA).

\section{Results}

\subsection{General results}

Forty-four medical students were excluded because they either did not return the questionnaire or did not fill it out completely. Therefore, 259 questionnaires were analyzed (response rate $=85.5 \%$ ). The average age of respondents for the three educational levels was $25 \pm 3.52$ years. All of the hospitals in which the study was conducted were referral settings in Kerman Province that deliver diverse medical services for the covered community. More than two-thirds of the participants were females (70.2\%). Most of the participants $(119,45.9 \%)$ were on externships, extern with $45.9 \%$ (119), followed by those on assistantships and internships.

\subsection{Expectation scores report}

From the perspective of those on externships, the highest and lowest expectation scores were the empathy and assurance dimensions, which were rated as 6.34 and 5.96, respectively. From the perspective of those on internships, the highest and lowest expectation scores were the empathy and responsiveness dimensions, which were rated as 5.5 and 5.13, respectively. From the perspective of those on assistanceships, the highest expectation scores were the responsiveness and assurance dimensions, at 5.88 and 5.85, respectively, with the tangibles dimension having the lowest expectations score, i.e., 5.54.

\subsection{Perception scores report}

The perceptions of those on externships indicated that the highest score were related to reliability, tangibles, and empathy of services with 5.08, 5.06, and 5.06, respectively, and the lowest score was associated with the responsiveness in medical education of the hospitals. This last issue, responsiveness of services, was similar for students with internships and assistantships, i.e., 3.77 and 3.84, respectively. The highest mean of perception score in intern students was attributed to the reliability (4.26) and assurance (4.25) dimensions. Also, the highest average among students with assistantships was reliability of services, i.e., 4.18.

\subsection{Gap service report}

The findings in medical education services of hospital settings indicated that there were negative quality gaps in all five SERVQUAL dimensions. The lowest and highest quality gaps were observed in the assurance and responsiveness dimensions, respectively. Table 1 provides the five SERVQUAL gaps across the three educational levels. These results indicated that there was an overall service quality shortfall of -1.35 .

Table 1. Summary of students' gap of SERVQUAL dimensions across three teaching hospitals

\begin{tabular}{|l|l|l|l|l|l|l|}
\hline Dimensions & Perceptions \pm SD & $\begin{array}{l}\text { Expectations } \pm \\
\text { SD }\end{array}$ & $\begin{array}{l}\text { Service gaps } \pm \\
\text { SD }\end{array}$ & Weight & Rank & $\mathrm{p}$ \\
\hline Assurance & $4.59 \pm 1.4$ & $5.77 \pm 1.19$ & $-1.18 \pm 2.19$ & $18.79 \pm 8.03$ & 5 & $<0.001$ \\
\hline Responsiveness & $4.26 \pm 1.68$ & $5.82 \pm 1.36$ & $-1.56 \pm 2.64$ & $21.14 \pm 8.42$ & 1 & $<0.001$ \\
\hline Empathy & $4.54 \pm 1.52$ & $5.94 \pm 1.29$ & $-1.4 \pm 2.49$ & $18.37 \pm 6.8$ & 2 & $<0.001$ \\
\hline Reliability & $4.66 \pm 1.45$ & $5.93 \pm 1.25$ & $-1.27 \pm 2.32$ & $20.04 \pm 8.2$ & 3 & $<0.001$ \\
\hline Tangibles & $4.55 \pm 1.52$ & $5.76 \pm 1.33$ & $-1.21 \pm 2.39$ & $18.42 \pm 8.65$ & 4 & $<0.001$ \\
\hline
\end{tabular}

This was due in part to the relatively poor scores in the important dimensions of responsiveness and empathy, which were -1.56 and -1.40 , respectively. There were significant differences between the perceptions and expectations of students in all five SERVQUAL dimensions $(\mathrm{p}<0.001)$. There were negative quality gaps in all of the items, and there were significant differences between perceptions and expectations of students in all of them $(\mathrm{p}<0.001)$. Analysis of the items that contributed the most to these poor scores indicated that the main causes of the dissatisfaction among the medical students were that their views and suggestions for changes in the curriculum were ignored and the disrespectful treatment they received from members of the hospital's staff (Table 2). 
Table 2. Items that contributed most to the negative gap in each dimension

\begin{tabular}{|c|c|c|c|c|c|c|}
\hline \multirow{2}{*}{\multicolumn{2}{|c|}{ Items in the modified questionnaire }} & \multirow{3}{*}{$\begin{array}{l}\mathrm{P}^{\mathrm{a}} \\
4.43\end{array}$} & \multirow{3}{*}{$\begin{array}{l}\mathrm{E}^{\mathrm{b}} \\
5.71\end{array}$} & \multirow{3}{*}{$\begin{array}{l}\text { Gap } \\
-1.28\end{array}$} & \multicolumn{2}{|c|}{ Paired t-test } \\
\hline & & & & & \multirow{2}{*}{$\begin{array}{l}\mathrm{t} \\
-13.75\end{array}$} & \multirow{2}{*}{$\begin{array}{l}\mathrm{p} \\
<0.001\end{array}$} \\
\hline Assurance & $\begin{array}{l}\text { Facilitating discussion and interaction about } \\
\text { case seminars in hospital }\end{array}$ & & & & & \\
\hline & $\begin{array}{l}\text { Qualifying students for future jobs by attaining } \\
\text { skills and practices }{ }^{c}\end{array}$ & 4.48 & 5.88 & $-1.4^{c}$ & -14.73 & $<0.001$ \\
\hline & $\begin{array}{l}\text { Accessibility of faculty members outside of case } \\
\text { seminars to answer students' questions }\end{array}$ & 4.14 & 5.49 & -1.35 & -13.99 & $<0.001$ \\
\hline & $\begin{array}{l}\text { Accessibility of adequate references to increase } \\
\text { students' professional knowledge }\end{array}$ & 4.66 & 5.83 & -1.17 & -14.1 & $<0.001$ \\
\hline & $\begin{array}{l}\text { Adequacy of faculty members' professional } \\
\text { knowledge and skills }\end{array}$ & 4.9 & 6.10 & -1.2 & -13.97 & $<0.001$ \\
\hline \multirow[t]{5}{*}{ Responsiveness } & $\begin{array}{l}\text { Introducing suitable references to students for } \\
\text { reading }\end{array}$ & 4.66 & 5.6 & -0.94 & -11.07 & $<0.001$ \\
\hline & $\begin{array}{l}\text { Supervisors' accessibility when students need } \\
\text { them }\end{array}$ & 4.23 & 5.93 & -1.7 & -16.2 & $<0.001$ \\
\hline & $\begin{array}{l}\text { Easy accessibility of administrators for students } \\
\text { to express views about the curriculum }\end{array}$ & 4.24 & 5.88 & -1.64 & -15.19 & $<0.001$ \\
\hline & $\begin{array}{l}\text { Considering students' views and suggestions in } \\
\text { the curriculum }^{c}\end{array}$ & 4.12 & 5.86 & $-1.74^{c}$ & -16.02 & $<0.001$ \\
\hline & $\begin{array}{l}\text { Declaring hours that students can refer to faculty } \\
\text { members to talk about educational problems }\end{array}$ & 4.02 & 5.7 & -1.68 & -15.95 & $<0.001$ \\
\hline \multirow[t]{6}{*}{ Empathy } & Assigning suitable and relevant homework & 4.23 & 5.61 & -1.38 & -13.16 & $<0.001$ \\
\hline & $\begin{array}{l}\text { Faculty members' flexibility when considering } \\
\text { the specific conditions of each student }\end{array}$ & 4.56 & 5.9 & -1.34 & -12.69 & $<0.001$ \\
\hline & Convenience of class hours & 4.47 & 6.07 & -1.6 & -15.31 & $<0.001$ \\
\hline & $\begin{array}{l}\text { Existence of silent and convenient place in } \\
\text { school for reading }\end{array}$ & 4.54 & 5.95 & -1.41 & -13.94 & $<0.001$ \\
\hline & $\begin{array}{l}\text { Respectful treatment of students by the hospital } \\
\text { staff }^{c}\end{array}$ & 4.31 & 5.95 & $-1.64^{c}$ & -15.64 & $<0.001$ \\
\hline & $\begin{array}{l}\text { Respectful treatment of students by the faculty } \\
\text { members }\end{array}$ & 4.97 & 6.0 & -1.03 & -11.57 & $<0.001$ \\
\hline \multirow[t]{6}{*}{ Reliability } & $\begin{array}{l}\text { Easy accessibility of available references in the } \\
\text { hospital }^{c}\end{array}$ & 4.57 & 6.01 & $-1.44^{c}$ & -16.45 & $<0.001$ \\
\hline & Presenting relevant educational content regularly & 4.64 & 6.0 & -1.36 & -14.42 & $<0.001$ \\
\hline & $\begin{array}{l}\text { Informing students concerning the results of } \\
\text { examinations }\end{array}$ & 4.41 & 5.79 & -1.38 & -14.3 & $<0.001$ \\
\hline & $\begin{array}{l}\text { Faculty members and staff fulfilling their } \\
\text { responsibilities in the promised time }\end{array}$ & 4.72 & 5.83 & -1.11 & -11.97 & $<0.001$ \\
\hline & $\begin{array}{l}\text { Understandable presentations of materials and } \\
\text { content }\end{array}$ & 4.65 & 5.88 & -1.23 & -12.99 & $<0.001$ \\
\hline & Gaining higher scores if students attempt more & 4.68 & 6.02 & -1.34 & -14.21 & $<0.001$ \\
\hline \multirow[t]{4}{*}{ Tangibles } & $\begin{array}{l}\text { Physical facilities that are visually appealing and } \\
\text { comfortable }^{c}\end{array}$ & 4.29 & 5.79 & $-1.5^{c}$ & -14.11 & $<0.001$ \\
\hline & $\begin{array}{l}\text { Up-to-date materials and educational equipment } \\
\text { in the hospital }\end{array}$ & 4.46 & 5.9 & -1.44 & -14.63 & $<0.001$ \\
\hline & $\begin{array}{l}\text { Neat and professional appearance of faculty } \\
\text { members and staff }\end{array}$ & 4.95 & 5.62 & -.067 & -7.91 & $<0.001$ \\
\hline & Visual appealing teaching tools & 4.41 & 5.77 & -1.36 & -14.94 & $<0.001$ \\
\hline
\end{tabular}

a: Perceptions; b: Exceptions; c: Items contributing most to negative gap in 5 scales

The detailed examination indicated that the students on externships had the highest quality gaps in the empathy and responsiveness dimensions. For the students on internships and assistantships, the responsiveness dimension had the 
highest gap. Also from the perspective of those with externships, the least educational quality gap was attributed to assurance, but those on internships and assistantships indicated that the least gap was in the tangible dimension. Surprisingly, it was noted that the mean quality gap for all of the dimensions was highest among the students on assistantships and lowest among the students on externships, with the mean of those on internships falling between the other two means. So, it could be perceived that students on assistantships had less satisfaction than either the interns or externs in all of the SERVQUAL dimensions (Table 3). Also, there was a significant difference between both between perceptions and expectations of the students in the externship, internship, and assistance levels. The results of Tukey and LSD post hoc showed a significant difference between externship for both internship and assistant, but there was no significant difference between internship and assistant. Also, in expectations, there was a significant difference between assistant with externship and internship, but there was no significant difference between externship and internship in any of the dimensions except assurance of services. In end of questionnaire we asked respondents to weigh and to prioritize five dimensions of SERVQUAL based on importance in medical education settings. The results showed that responsiveness (weight $=21.14$ out of 100 scores) and empathy (weight $=18.37$ out of 100 scores) were considered to be the most and the least important, respectively (Table 1 ).

Table 3. Students' perceptions, expectations, and quality gaps disaggregated by various educational levels

\begin{tabular}{|c|c|c|c|c|}
\hline Dimensions & Educational Level & Perception & Expectation & Service Gap \\
\hline \multirow[t]{4}{*}{ Assurance } & Externship & 4.96 & 5.96 & -1.0 \\
\hline & Internship & 4.25 & 5.43 & -1.18 \\
\hline & Assistance & 4.07 & 5.85 & -1.78 \\
\hline & Kruskal-Wallis & $\mathrm{p}<0.001$ & $\mathrm{p}<0.001$ & $\mathrm{p}<0.001$ \\
\hline \multirow[t]{4}{*}{ Responsiveness } & Externship & 4.77 & 6.04 & -1.27 \\
\hline & Internship & 3.77 & 5.13 & -1.36 \\
\hline & Assistance & 3.84 & 5.88 & -2.04 \\
\hline & Kruskal-Wallis & $\mathrm{p}<0.001$ & $\mathrm{p}<0.001$ & $\mathrm{p}<0.001$ \\
\hline \multirow[t]{4}{*}{ Empathy } & Externship & 5.06 & 6.34 & -1.28 \\
\hline & Internship & 4.17 & 5.5 & -1.33 \\
\hline & Assistance & 3.94 & 5.72 & -1.78 \\
\hline & Kruskal-Wallis & $\mathrm{p}<0.001$ & $\mathrm{p}<0.001$ & $\mathrm{p}<0.001$ \\
\hline \multirow[t]{4}{*}{ Reliability } & Externship & 5.08 & 6.17 & -1.09 \\
\hline & Internship & 4.26 & 5.45 & -1.19 \\
\hline & Assistance & 4.18 & 5.78 & -1.6 \\
\hline & Kruskal-Wallis & $\mathrm{p}<0.001$ & $\mathrm{p}<0.001$ & $\mathrm{p}<0.001$ \\
\hline \multirow[t]{4}{*}{ Tangibles } & Externship & 5.06 & 6.24 & -1.18 \\
\hline & Internship & 4.09 & 5.18 & -1.09 \\
\hline & Assistance & 4.06 & 5.54 & -1.48 \\
\hline & Kruskal-Wallis & $\mathrm{p}<0.001$ & $\mathrm{p}<0.001$ & $\mathrm{p}<0.001$ \\
\hline
\end{tabular}

\section{Discussion}

The purpose of this study was to determine the gaps in the service quality of clinical education services. This was accomplished by using a modified SERVQUAL instrument among medical students in teaching hospitals affiliated with the Kerman University of Medical Sciences. Overall, as the findings showed in all of the five SERVQUAL dimensions, there was a negative quality gap. This supports the results of studies conducted by Aghamolaei and Zare (22), Kebriaei and Roudbari (23), Barnes (24), and Rahim Khanli et al. (17).

In this study, the least negative and the most negative quality gaps were in the assurance and responsiveness dimensions, respectively. Also, other studies $(22,23)$ in Zahedan and Hormozgan Provinces have indicated that responsiveness has the greatest quality gap in medical institutions. The observed gap in the responsiveness dimension indicated that instructors were neither successful in introducing suitable references to students nor were they accessible when the students needed them. These shortcomings were attributed to the fact that attending physicians practice simultaneously in the public and private sector and often are in a hurry to get to their private practices, resulting in their being less than fully responsive to their students' needs. In this regard, previous studies have emphasized medical students' dissatisfaction with the small amount of time spent by instructors during their clinical education (25). Furthermore, the greatest negative gap of this dimension related to not considering students views and suggestions in curriculum development. This reflects the fact that the Iranian medical education system 
still is based on the traditional system of offering courses, which follows a discipline-based approach that is teachercentered and hospital-based with little, if any, concern for receiving students' feedback on educational issues (26). Epstein and Hundert defined competency as "the habitual and judicious use of communication, knowledge, technical skills, clinical reasoning, emotions, values, and reflection in daily practice for the benefit of the individuals and communities being served" (27). To guarantee proficiency, teaching hospitals should offer official teaching programs and revised courses for procedures, resuscitation ("codes"), and other specialty-specific duties instead of relying on self-learning, which is quite variable, and "learning by doing" (28). Also according to Nip and Haruno's (29) and Nadel et al.'s (30) studies, there is evidence that workshops and training improve competence in performing procedures. However, the results of this study indicated that the students' perception of the potential of the current curriculum for preparing them to fulfill their future professional responsibilities was one of the other items that contributed most to the negative gap. These findings show there are some weaknesses in the organization and delivery of the curriculum with respect to the desired outcome of individual competency, e.g., the discordance between practical and theoretical courses and unnecessary emphasis on rare cases as opposed to prevalent cases. Empathy in an organization means the access to, communication with, and understanding of the customer in the process of caring for and providing individualized attention (31). In this case, the item of behavior of hospitals' staff with students received the greatest negative gap, which calls for hospitals administrators' better engagement in this regard by providing interpersonal skills training for staff and students, as well as the implementation of a planned approach to coordination and communication among staff and medical students. Also, implementing formal orientation programs for students and staff would likely provide significant benefits. These approaches would increase the students' satisfaction and, as Volpp and Grande (28) suggested, result in the reduction of medical errors.

The reliability dimension of the SERQUAL was defined as "Ability to perform the promised service dependably and accurately," and it had a negative gap like the other dimensions in the studied hospitals. Our detailed investigation of this dimension indicated that the lack of easy access to available references in hospitals was the major contributor to this gap, in that electronic and library references were not sufficient in the hospital settings, even though such references should be developed both quantitatively and qualitatively in hospitals. In this regard, Rahim Khanli et al. reported that the reliability dimension had the least quality gap (17). One of the other dimensions in SERVQUAL is related to physical facilities, equipment, and the appearance of personnel involved in the educational process. It was found that the visual appeal and comfort levels of the physical facilities had the greatest quality gap. This indicated that the hospitals do not have efficient and modern educational facilities compatible with the expert fields they are addressing. In this regard, a study among medical students indicated that the maximum service quality gap was in the tangibles dimension (32). Clinical education is one of the key components of resource generation, which itself is one the functions of the healthcare system as proposed by the World Health Organization (WHO). Considering the huge investment on this field and the lasting effects of medical education on the health status of a society and the utilization of resources, any society should ensure that it is providing high quality clinical education.

This study had at least two main limitations. First, the students shifted frequently among the three hospitals, which made it difficult to distribute and collect the questionnaires. Second, the diverse medical departments in teaching hospitals have different performances, which was not addressed in this study.

\section{Conclusions}

The results of this study indicated that the quality of clinical education services did not satisfy the students' expectations. The SERVQUAL approach provided the possibility of recognizing quality issues by their core dimensions as well as the items in each dimension. As we carefully examined the dimensions and the items that had the higher quality gaps, it was clear that, for the most part, clinical education officials can improve the quality by designing interventions, which would not be very difficult to design or implement. In addition, the results of this study indicated that the quality gap increases as the number of students in the hospital increases. This suggested that educational staff and hospital administrators should pay better attention to satisfaction of interns and assistants, in particular. It is evident that these two groups in teaching hospitals certainly provide most of the care that patients receive. So, it can be inferred that their higher satisfaction can lead to significant improvements in clinical effectiveness. Overall, improvements are needed across all five SERVQUAL dimensions. It is suggested that the education departments or the Deputy of Education reorganize the delivery of services to improve the students' satisfaction. Also, it is suggested that additional research be conducted concerning how to assess the quality of clinical education services using other models that encompass broader measures of the delivered services. 


\section{Acknowledgments:}

The authors thank the Kerman University of Medical Sciences for supporting this research.

\section{Conflict of Interest:}

There is no conflict of interest to be declared.

\section{Authors' contributions:}

All authors contributed to this project and article equally. All authors read and approved the final manuscript.

\section{References}

1) Chen L, Evans T, Anand S, Boufford JI, Brown H, Chowdhury M, et al. Human resources for health: overcoming the crisis. Lancet 2004; 364 (9449): 1984-90. doi: 10.1016/S0140-6736(04)17482-5

2) Margolis PA, Lannon CM, Stuart JM, Fried BJ, Keyes-Elstein L, Moore DE. Practice based education to improve delivery systems for prevention in primary care: randomised trial. BMJ 2004; 328 (7436): 388. doi: 10.1136/bmj.38009.706319.47. PMID: 14766718, PMCID: PMC341391

3) Biggs J. The reflective institution: Assuring and enhancing the quality of teaching and learning. High Educ 2001; 41: 221-38. doi: 10.1023/A:1004181331049.

4) Measuring Quality and Performance in Higher Education. Qual High Educ 2001; 7 (1): 47-54. doi: 10.1080/13538320120045076

5) Tan KC, Kek SW. Service quality in higher education using an enhanced SERVQUAL approach. Qual High Educ 2004; 10 (1): 18-24. doi: 10.1080/1353832242000195032

6) Mehrdad R. Health system in Iran. JMAJ 2009; 52 (1): 69-73.

7) Azizi F. The reform of medical education in Iran. Med Educ 1997; 34 (3): 159-62. doi: 10.1111/j.13652923.1997.tb02559.x

8) Clewes D. A Student-centred Conceptual Model of Service Quality in Higher Education. Qual High Educ 2003; 9 (1): 69-85. doi: 10.1080/13538320308163

9) Tam M. Measuring Quality and Performance in Higher Education. Qual High Educ 2001; 7 (1): 47-54. doi: 10.1080/13538320120045076

10) Hill Y, Lomas L, Macgregor J. Students' perceptions of quality in higher education. Quality Assurance Educ 2003; 11 (1): 15-20. doi: 10.1108/09684880310462047

11) Elliott KM, Shin D. Student Satisfaction: An alternative approach to assessing this important concept. J High Educ Pol Manag 2002; 24 (2): 197-209. doi: 10.1080/1360080022000013518

12) Distler JW. Critical thinking and clinical competence: Result of the implementation of student-centered teaching strategies in an advanced practice nurse curriculum. Nurs Educ Prac 2007; 7 (1): 53-9. doi: 10.1016/j.nepr.2006.08.003. PMID: 17689424

13) Worrell JA, Profetto-McGrath J. Critical thinking as an outcome of context-based learning among post RN students: A literature review. Nurs Educ Today 2007; 27 (5): 420-6. doi: 10.1016/j.nedt.2006.07.004. PMID: 16945453

14) Ozturk C, Muslu GK, Dicle A. A comparison of problem-based and traditional education on nursing students' critical thinking disposition. Nurs Educ Today 2008; 28 (5): 627-32. doi: 10.1016/j.nedt.2007.10.001. PMID: 18054412

15) De Oliviera OJ, Ferreira EC. Adaptation and application of the SERVQUAL scale in higher education. POMS 20th Annual Conference; 2009 May 1-4; Orlando, USA; Florida; 2009.

16) Parasuraman A, Berry LL, Zeithaml VA. SERVQUAL: a multiple-item scale for measuring consumer perceptions of service quality. J Retailing 1988; 64 (1): 12-40.

17) Rahim Khanli M, Daneshmandi H, Choobineh A. The students' viewpoint on the quality gap in educational services. J Adv Med Educ Prof. 2014; 2 (3): 114-9. PMID: 25512931, PMCID: PMC4235544

18) Kwan P, Ng P. Quality indicators in higher education-comparing Hong Kong and China's students. Manag Audit J 1999; 14 (1/2): 20-77. doi: 10.1108/02686909910245964

19) Oldfield B, Baron S. Student perceptions of service quality in a UK university Business and management faculty. Qual Assur Educ 2000; 8 (2): 85-95. doi: 10.1108/09684880010325600

20) Ladhari R. A review of twenty years of SERVQUAL research. International Journal of Quality and Service Sciences 2009; 1 (2): 172-98. doi: 10.1108/17566690910971445

21) Karydis A, Komboli-Kodovazeniti M, Hatzigeorgiou D, Panis V. Expectations and perceptions of Greek patients regarding the quality of dental health care. Int J Qual Health Care 2001; 13 (5): 409-16. doi: 10.1093/intqhe/13.5.409. PMID: 11669569 
22) Aghamolaei T, Zare Sh. Quality gap of educational services in viewpoints of students in Hormozgan University of medical sciences. BMC Medical Education 2008; 8: 34. doi: 10.1186/1472-6920-8-34. PMID: 18564413, PMCID:PMC2442591.

23) Kebriaei A, Roudbari M. Quality gap in educational services at Zahedan university of medical sciences: students viewpoints about current and optimal condition. Iranian Journal of Medical Education 2005; 5 (1): 53-60. [In Persian]

24) Barnes BR. Analysing Service Quality: The Case of Post-Graduate Chinese Students. Total Quality Management \& Business Excellence. 2007; 18 (3): 313-31. doi: 10.1080/14783360601152558

25) Garakyaraghi M, Sabouri M, Avizhegan M, Ebrahimi A, Zolfaghari M. Interns' viewpoints on assistants teaching status in Esfahan University of Medical Sciences. Iranian Journal of Medical Education 2007; 7(2): 361-9. [In Persian]

26) Tavakol M, Murphy R, Torabi S. Medical Education in Iran: An Exploration of Some Curriculum Issues. Med Educ Online 2006; 11 (5): 1-8. doi: 10.3402/meo.v11i.4585

27) Epstein RM, Hundert EM. Defining and assessing professional competence. JAMA 2002; 287: 226-35. doi: 10.1001/jama.287.2.226.

28) Volpp K, Grande D. Residents' Suggestions for Reducing Errors in Teaching Hospitals. NEJM 2003 ; 348 (9): 851-5. doi: 10.1056/nejmsb021667. PMID: 12606742

29) Nip IL, Haruno MM. A systematic approach to teaching insertion of a central venous line. Acad Med 2000; 75: 552. doi: 10.1097/00001888-200005000-00083. PMID: 10824835

30) Nadel FM, Lavelle JM, Fein JA, Giardino AP, Decker JM, Durbin DR. Teaching resuscitation to pediatric residents: the effects of an intervention. Arch Pediatr Adolesc Med 2000; 154 (10): 1049-54. doi: 10.1001/archpedi.154.10.1049. PMID: 11030858

31) Nekoei-Moghadam M, Amiresmaili M. Hospitals of Kerman University of Medical Sciences, as a tangible example of a developing country. Int J Health Care Qual Assur 2011; 24 (1): 57-66. doi: 10.1108/09526861111098247. PMID: 21456498

32) Tabarraei M, Mohebi S. Assessing the Quality of Educational Services from the Viewpoint of Medical Students of Islamic Azad University of Qom based on SERVQUAL Model- 2013. Arch Hyg Sci 2014; 3 (2): 50-8. 